\title{
Comparative cardiovascular effects of thiazolidinediones: systematic review and meta-analysis of observational studies
}

\author{
Yoon Kong Loke, senior lecturer in clinical pharmacology, ${ }^{1}$ Chun Shing Kwok, medical student, ${ }^{1}$ Sonal Singh, \\ assistant professor of medicine ${ }^{2}$
}

\begin{abstract}
${ }^{1}$ School of Medicine, Health Policy and Practice, University of East Anglia, Norwich NR4 7TJ, UK

${ }_{2}^{2}$ Johns Hopkins University School of Medicine, Baltimore, MD 21283, USA

Correspondence to: Y K Loke y.loke@uea.ac.uk
\end{abstract}

Cite this as: BMJ 2011;342:d1309 doi:10.1136/bmi.d1309

\section{ABSTRACT}

Objective To determine the comparative effects of the thiazolidinediones (rosiglitazone and pioglitazone) on myocardial infarction, congestive heart failure, and mortality in patients with type 2 diabetes.

Design Systematic review and meta-analysis of observational studies.

Data sources Searches of Medline and Embase in September 2010.

Study selection Observational studies that directly compared the risk of cardiovascular outcomes for rosiglitazone and pioglitazone among patients with type 2 diabetes mellitus were included.

Data extraction Random effects meta-analysis (inverse variance method) was used to calculate the odds ratios for cardiovascular outcomes with thiazolidinedione use. The $I^{2}$ statistic was used to assess statistical heterogeneity.

Results Cardiovascular outcomes from 16 observational studies ( 4 case-control studies and 12 retrospective cohort studies), including 810000 thiazolidinedione users, were evaluated after a detailed review of 189 citations. Compared with pioglitazone, use of rosiglitazone was associated with a statistically significant increase in the odds of myocardial infarction ( $n=15$ studies; odds ratio $1.16,95 \%$ confidence interval 1.07 to $1.24 ; P<0.001 ; I^{2}=46 \%$ ), congestive heart failure $\left(n=8 ; 1.22,1.14\right.$ to $\left.1.31 ; P<0.001 ; I^{2}=37 \%\right)$, and death $\left(n=8 ; 1.14,1.09\right.$ to $\left.1.20 ; P<0.001 ; I^{2}=0 \%\right)$. Numbers needed to treat to harm ( $\mathrm{NNH})$, depending on the population at risk, suggest 170 excess myocardial infarctions, 649 excess cases of heart failure, and 431 excess deaths for every 100000 patients who receive rosiglitazone rather than pioglitazone.

Conclusion Among patients with type 2 diabetes, use of rosiglitazone is associated with significantly higher odds of congestive heart failure, myocardial infarction, and death relative to pioglitazone in real world settings.

\section{INTRODUCTION}

Troglitazone, the first thiazolidinedione, was withdrawn from the market because of liver toxicity. ${ }^{1}$ Muraglitazar, a dual peroxisome proliferator activated receptor (PPAR) agonist, failed to achieve regulatory approval because of concerns about adverse cardiovascular events. ${ }^{2}$ Rosiglitazone and pioglitazone are the available thiazolidinediones in North America, but meta-analyses of randomised controlled trials have suggested an increased risk of ischaemic cardiovascular events with rosiglitazone. ${ }^{34}$ In contrast, meta-analysis of trials of pioglitazone indicates the possibility of an ischaemic cardiovascular benefit. ${ }^{5}$ Robust evidence also shows that both drugs increase the risk of congestive heart failure and fractures, but whether any meaningful difference exists in the magnitude of risk between the two thiazolidinediones is not known. ${ }^{67}$ The European Medicines Agency has recommended the suspension of marketing authorisation for rosiglitazone, whereas the US Food and Drug Administration has allowed the continued marketing of rosiglitazone with additional restrictions. ${ }^{8}$

No long term trials with cardiovascular outcomes have directly compared these two drugs. Clinical trials have strict selection criteria that may exclude participants at high risk of adverse events, and adverse cardiovascular outcomes can be rare in such trials. ${ }^{9}$ On the other hand, population based observational studies resemble clinical practice, where patients may have risk factors for cardiovascular disease or comorbidities. Therefore, consideration of the evidence from carefully conducted observational studies is essential to determine if any difference in cardiovascular events or mortality exists between the two drugs.

Our objective was to systematically determine the comparative effects of rosiglitazone and pioglitazone on cardiovascular outcomes (myocardial infarction and congestive heart failure) and mortality from observational studies in patients with type 2 diabetes. We aimed specifically to calculate the pooled odds ratios for adverse cardiovascular events with rosiglitazone compared with pioglitazone - that is, the relative likelihood of cardiovascular harm if rosiglitazone was used rather than pioglitazone.

\section{METHODS}

\section{Eligibility criteria}

We selected controlled observational (non-randomised) studies that reported on cardiac outcomes in patients receiving rosiglitazone compared with pioglitazone. 


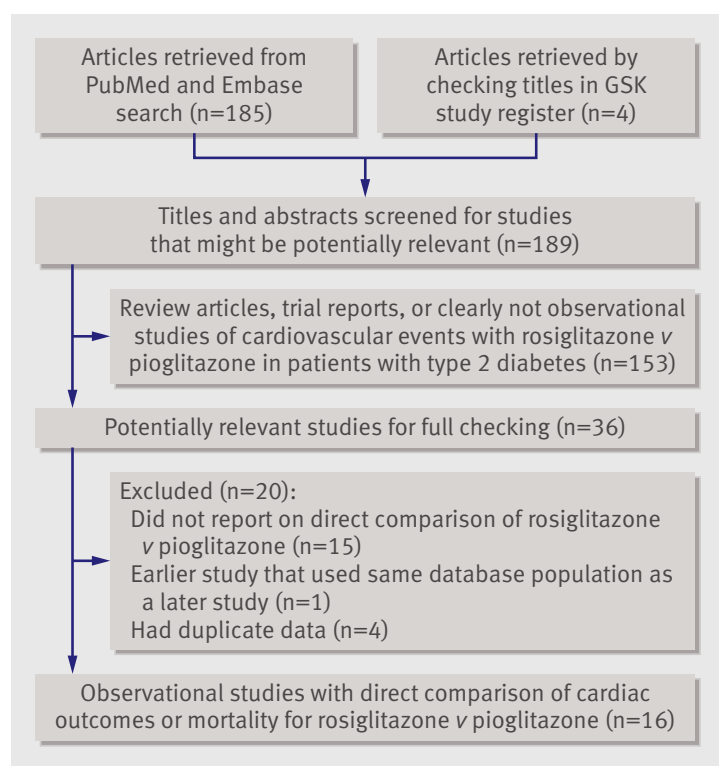

Fig 1 | Flow diagram of process of selection of articles for meta-analysis. GSK=GlaxoSmithKline

We included studies of a cohort or case-control design that enrolled participants with type 2 diabetes mellitus. The primary outcome of interest was myocardial infarction. Secondary outcome measures were congestive heart failure and overall mortality. Eligible studies had to present one of the following: odds ratio, relative risk, hazard ratio, or sufficient raw data to enable calculation of the odds ratio where not otherwise reported.

\section{Search strategy}

We searched Medline and Embase by using Ovid SP (from inception to the end of September 2010), with the search terms (pioglitazone or rosiglitazone or thiazolidinedione\$).mp and (myocardial-infarction or cardiovascular or cardiac or heart).mp and (cohort or case-control or observational or retrospective).mp. We did not use any language restrictions, but we limited the search to human studies. Additionally, we signed up with PubMed to receive automated electronic notification of any new articles containing the above search terms. To identify unpublished studies, we reviewed the regulatory authorities websites (US Food and Drug Administration and European Medicines Agency), as well as the study registers of the drug manufacturers GlaxoSmithKline and Takeda. We checked the bibliographies of included studies and recent review articles for additional relevant articles.

\section{Study selection and data extraction}

Two reviewers (CSK and YKL or SS) checked all titles and abstracts for studies that could potentially meet the inclusion criteria. We retrieved full reports of these potentially eligible studies for detailed assessment by two reviewers (CSK and YKL), who then independently extracted information on study design, drug use, study location, characteristics of participants, and relevant outcomes on to a preformatted spreadsheet.
Any uncertainties or discrepancies between the two reviewers were resolved through consensus after rechecking of the source data and consultation with the third reviewer. We also contacted authors if any areas of uncertainty needed clarification.

Where different timings and durations of thiazolidinedione use were reported in the study participants, we pre-specified that data would be preferentially extracted from the participants with current or most recent use, until cessation of treatment. We also aimed to extract risk estimates pertaining to overall use in the entire cohort rather than in any specific subgroups.

\section{Risk of bias}

In accordance with the recommendations of the Cochrane Adverse Effects Methods Group, we checked the methods of selection of participants (including baseline characteristics and adjustment for confounders), nature of follow-up, ascertainment of drug use, and definition and monitoring of adverse outcomes. ${ }^{10}$ To counter selective reporting bias, we contacted authors when relevant cardiovascular outcomes were potentially measured but were not reported or were stated to be non-significant. We used a funnel plot to assess publication bias.

\section{Data analysis}

We used RevMan 5.0.25 (Nordic Cochrane Centre) to do random effects meta-analysis using the inverse variance method for pooled odds ratios. We used the fixed effects model for sensitivity analysis. We assumed similarity between the odds ratio and other relative measures such as relative risk, rate ratios, or hazard ratios because cardiovascular events and deaths were rare events. ${ }^{11}$

Where possible, we aimed to pool adjusted odds ratios from the primary studies; otherwise, we used raw outcome data to yield unadjusted odds ratios. In view of the potential diversity of study designs, we grouped the studies for the analysis according to studies for which only the unadjusted odds ratios were available, with no correction for baseline differences or confounding, and those for which we were able to extract odds ratios adjusted for potential confounders.

For consistency in direction of risk comparisons, we used the odds ratio to assess the magnitude of risk for rosiglitazone use compared with that for pioglitazone use. For studies that reported the odds ratio for pioglitazone compared with rosiglitazone, we used the reciprocal of the point estimate and the bounds of the confidence intervals.

We estimated the number needed to treat to harm per year $(\mathrm{NNH})$ (and 95\% confidence interval) by applying the pooled odds ratio from the meta-analysis to the annual rate of the event in different populations. ${ }^{12}$ The NNH is the number of patients with type 2 diabetes who need to be treated with rosiglitazone rather than pioglitazone for one additional patient to have an adverse outcome. 


\section{Table 1|Design and characteristics of included studies}

\begin{tabular}{|c|c|}
\hline Studies & Study design and data source \\
\hline Bilik $2010^{14}$ & $\begin{array}{l}\text { Retrospective cohort study (TRIAD); } \\
\text { community patients; USA, } 1999 \text { to } \\
2003\end{array}$ \\
\hline $\begin{array}{l}\text { Brownstein } \\
2010^{15}\end{array}$ & $\begin{array}{l}\text { Retrospective cohort study in } \\
\text { Partners Healthcare System } \\
\text { covering hospital and community } \\
\text { patients; USA, January } 2000 \text { to July } \\
2006\end{array}$ \\
\hline $\begin{array}{l}\text { Dormuth } \\
2009^{16}\end{array}$ & $\begin{array}{l}\text { Nested case-control study; } \\
\text { hospital and community patients; } \\
\text { Pharmanet database, BC, Canada, } \\
\text { May } 2003 \text { to March } 2007\end{array}$ \\
\hline
\end{tabular}

Graham 2010 ${ }^{17}$ New user inception cohort community patients; Medicare, USA, July 2006 to June 2009

\section{No of patients}

564 rosiglitazone; 334 pioglitazone (in health plans in which both thiazolidinediones were available)

1879 rosiglitazone; 806 pioglitazone Acute MI: 2244 cases and

8903 controls; drug use: 462 rosiglitazone and 235 pioglitazone

\section{3 rosiglitazone;} 159978 pioglitazone

\section{Hsiao $2009^{18} \quad$ Retrospective cohort study; $\mathrm{NH}$} claims database, Taiwan, 2000 to 12010 pioglitazone 2005

49624 rosiglitazone

\begin{tabular}{ll}
\hline Juurlink 2009 & Retrospective new user cohort \\
& Study; Ontario Public Drug Benefit \\
& Program, Canada, 2002 to 2008 \\
\hline Koro 2008 & $\begin{array}{l}\text { Nested case-control study within } \\
\text { diabetes cohort of Integrated } \\
\text { HealthCare Information Services } \\
\text { claims database; USA, 1999 to } \\
2006\end{array}$
\end{tabular}

Lipscombe Nested case-control study; $2007^{21} \quad$ community patients; Ontario, Canada, 2002 to 2005

16951 rosiglitazone 22785 pioglitazone. MI: 9870 cases and 29610 controls; drug use: 3839 rosiglitazone and 3343 pioglitazone

\section{6 current rosiglitazone} users; 929 current pioglitazone users
64
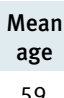

59 male 48 Selection criteria

Type 2 diabetes, age $>18$ years, not pregnant, community dwelling, English or Spanish speaking, and enrolled in health plan for $\geq 18$ months; excluded if $>1$ type of thiazolidinedione prescription

ged $>18$ years with diabetes or $\mathrm{HbA}_{1 \mathrm{C}}>6 \%$ and $\geq 1$ oral diabetes drug; excluded if used metformin or thiazolidinedione for polycystic ovaries
Risk estimates $(95 \% \mathrm{Cl})$

\section{Where both}

thiazolidinediones were available on formulary: MI HR 1.3 (0.31 to 5.37); mortality 0.69 (0.28 to 1.69 )

Based on entire cohort with adjustment for known risk factors: MI RR 1.7 (1.1 to 2.6)

\begin{tabular}{|c|c|c|c|c|c|c|}
\hline $\begin{array}{l}\text { Margolis } \\
2008^{22}\end{array}$ & $\begin{array}{l}\text { Retrospective cohort study; } \\
\text { community patients in THIN GP } \\
\text { database; UK, } 2002 \text { to } 2006\end{array}$ & $\begin{array}{l}7282 \text { rosiglitazone; } \\
2244 \text { pioglitazone }\end{array}$ & NA & 54 & $\begin{array}{l}\text { Patients with two records of diabetes between } 2002 \\
\text { and } 2006 \text { and } \geq 40 \text { years old }\end{array}$ & $\begin{array}{l}\text { Full cohort: MI or CAD HR } 1.0 \\
(0.8 \text { to } 1.3)\end{array}$ \\
\hline $\begin{array}{l}\text { Pantalone } \\
2009^{23}\end{array}$ & $\begin{array}{l}\text { Retrospective cohort study; } \\
\text { Cleveland Clinic Electronic Health } \\
\text { Records; USA, October } 1998 \text { to } \\
\text { October } 2006\end{array}$ & $\begin{array}{l}1079 \text { rosiglitazone; } \\
1508 \text { pioglitazone }\end{array}$ & 61 & 47 & $\begin{array}{l}\text { Type } 2 \text { diabetes with prescription for rosiglitazone, } \\
\text { pioglitazone, metformin, or sulfonylurea, age }>18 \text { years } \\
\text { with no history of dialysis, CAD, or HF; excluded if } \\
\text { prescribed insulin or multiple oral agents }\end{array}$ & $\begin{array}{l}\text { HF HR } 0.84 \text { ( } 0.52 \text { to } 1.35) ; \\
\text { mortality } 1.23 \text { ( } 0.79 \text { to } 1.92)\end{array}$ \\
\hline Stockl $2009^{24}$ & $\begin{array}{l}\text { Nested case-control study; claims } \\
\text { database of Prescription Solutions } \\
\text { cohort in } 5 \text { states in USA, January } \\
2000 \text { to June } 2006\end{array}$ & $\begin{array}{l}\text { MI: } 1681 \text { cases and } \\
6653 \text { controls; drug use: } \\
1039 \text { rosiglitazone and } \\
294 \text { pioglitazone }\end{array}$ & 70 & 55 & $\begin{array}{l}\text { Patients aged 18-84 years with a filled prescription for } \\
\text { antidiabetic drug or exenatide during study period; } \\
\text { excluded if had type } 1 \text { diabetes, cancer, renal or liver } \\
\text { failure, organ transplantation, or HIV infection }\end{array}$ & MI OR 1.26 (0.79 to 2.00$)$ \\
\hline $\begin{array}{l}\text { Tzoulaki } \\
2009^{25}\end{array}$ & $\begin{array}{l}\text { Retrospective cohort study; } \\
\text { community patients; UK General } \\
\text { Practice Research Database, } \\
\text { January } 1990 \text { to December } 2005\end{array}$ & $\begin{array}{l}140082 \text { rosiglitazone; } \\
45807 \text { pioglitazone }\end{array}$ & 65 & 52 & $\begin{array}{l}\text { Patients aged } 35-90 \text { years with episode of care } \\
\text { between } 1990 \text { and } 2005 \text { associated with clinical or } \\
\text { referred event for diabetes; excluded if date of death } \\
\text { unclear }\end{array}$ & $\begin{array}{l}\text { MI HR } 1.34 \text { (0.86 to } 2.09) ; \\
\text { HF } 1.04 \text { ( } 0.75 \text { to } 1.44) ; \\
\text { mortality } 1.36 \text { (1.05 to } 1.76)\end{array}$ \\
\hline Walker $2008^{26}$ & $\begin{array}{l}\text { Retrospective cohort study; } \\
\text { pharmacy and medical claims } \\
\text { database (Pharmetrics) covering } \\
>80 \text { health plans; USA, } 2000 \text { to } \\
2007\end{array}$ & $\begin{array}{l}57000 \text { rosiglitazone; } \\
51000 \text { pioglitazone }\end{array}$ & $<65$ & NA & $\begin{array}{l}\text { Users of oral hypoglycaemic agents who had } \\
\geq 6 \text { months' membership in health plan, age }>18 \text { years; } \\
\text { excluded if in health plans for which data had been } \\
\text { previously used in similar studies }\end{array}$ & $\begin{array}{l}\text { On treatment summary: } \\
\text { MI } 1.21(0.95 \text { to } 1.54)\end{array}$ \\
\hline Wertz $2010^{27}$ & $\begin{array}{l}\text { Retrospective cohort study; } \\
\text { medical/pharmacy claims in } \\
\text { WellPoint database; USA, January } \\
2001 \text { to December } 2005\end{array}$ & $\begin{array}{l}18319 \text { rosiglitazone; } \\
18309 \text { pioglitazone }\end{array}$ & 54 & 58 & $\begin{array}{l}\text { Aged }>18 \text { years with new rosiglitazone or pioglitazone } \\
\text { claim; excluded if not in health plan }>365 \text { days before } \\
\text { index date or had pre-index pharmacy claim of insulin; } \\
\text { those with previous cardiovascular events were not } \\
\text { excluded }\end{array}$ & $\begin{array}{l}\text { MI HR } 0.94 \text { ( } 0.75 \text { to } 1.18) ; \mathrm{HF} \\
1.10 \text { (0.94 to } 1.31) ; \text { mortality } \\
1.02 \text { (0.86 to } 1.21)\end{array}$ \\
\hline $\begin{array}{l}\text { Winkelmayer } \\
2008^{28}\end{array}$ & $\begin{array}{l}\text { New user cohort study; Medicare } \\
\text { database in New Jersey and } \\
\text { Pennsylvania, USA, January } 2000 \\
\text { to December } 2005\end{array}$ & $\begin{array}{l}14101 \text { rosiglitazone; } \\
14260 \text { pioglitazone }\end{array}$ & 76 & 26 & $\begin{array}{l}\text { Age }>65 \text { years with new prescription for } \\
\text { thiazolidinedione; excluded if used troglitazone or } \\
\text { fixed dose combination with metformin }\end{array}$ & $\begin{array}{l}\text { On-drug analysis: MI IRR } 1.08 \\
\text { (0.93 to } 1.25) ; \text { HF } 1.13(1.01 \\
\text { to } 1.26) ; \text { mortality } 1.15(1.05 \\
\text { to } 1.26)\end{array}$ \\
\hline Ziyadeh $2009^{29}$ & $\begin{array}{l}\text { Retrospective cohort study; i3 } \\
\text { proprietary research database of } \\
\text { medical claims in USA, July } 2000 \text { to } \\
\text { March } 2007\end{array}$ & $\begin{array}{l}47501 \text { rosiglitazone; } \\
47501 \text { pioglitazone }\end{array}$ & NA & 57 & $\begin{array}{l}\text { Age }>18 \text { years, starting rosiglitazone or pioglitazone, } \\
\text { followed by }>\text { months of health plan membership; } \\
\text { troglitazone users excluded }\end{array}$ & $\begin{array}{l}\text { Based on censoring at } \\
\text { discontinuation of treatment } \\
\text { (regimen stop): MI HR } 1.41 \\
(1.13 \text { to } 1.75)\end{array}$ \\
\hline
\end{tabular}




\section{Statistical heterogeneity}

We used the $\mathrm{I}^{2}$ statistic to assess statistical heterogeneity. $\mathrm{I}^{2}$ values of $30-60 \%$ represented a moderate level of heterogeneity. ${ }^{13}$

\section{RESULTS}

Figure 1 shows the process of selection of studies. We retrieved 16 observational studies involving 810000 thiazolidinedione users (429000 patients taking rosiglitazone and 381000 taking pioglitazone), after a detailed review of 189 citations. ${ }^{14-29}$ Fifteen studies reported on the outcome of myocardial infarction, eight studies reported on the outcome of congestive heart failure, and eight studies reported on mortality.

We found 12 retrospective cohort studies and four case-control studies. The mean or median follow-up time ranged from 105 days to 7.1 years. Four studies reported duration of thiazolidinedione use, with a range of 215 to 450 days. The mean age of participants ranged from 54 to 76 years across studies, but most study participants were generally aged above 60 years; only two studies reported the average age of their participants as under 60 years. An average of 55\%

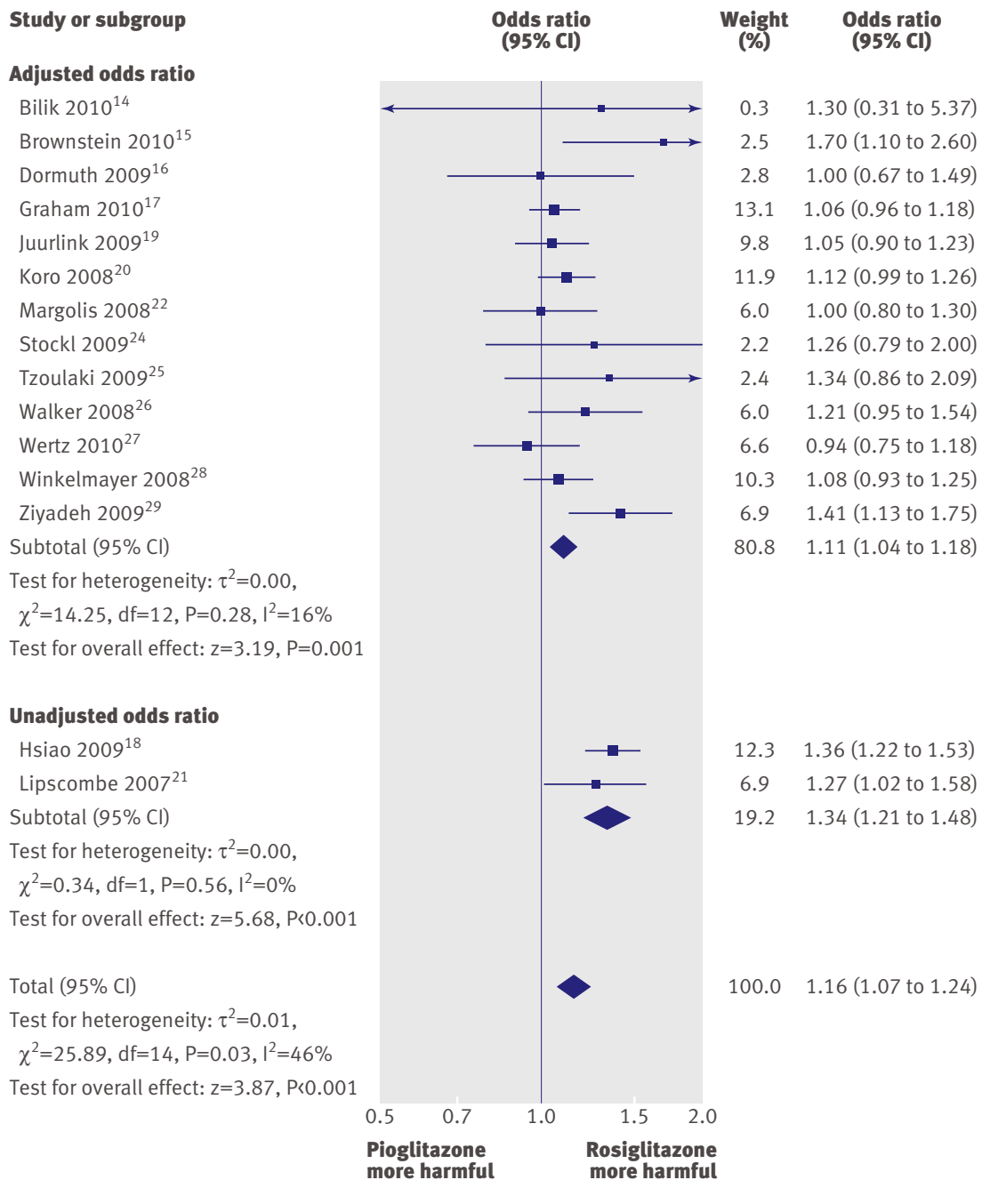

Fig 2 Meta-analysis of odds ratio for myocardial infarction with rosiglitazone versus pioglitazone of patients were male across 15 studies. Table 1 shows the main characteristics of the studies and participants; table 2 shows the outcomes, interventions, and quality assessments.

\section{Risk of bias}

The included studies were broadly similar in terms of ascertainment of drug use and cardiovascular outcomes (table 2); they relied mainly on computerised diagnostic codes, pharmacy claims databases, and retrospective chart reviews. Few researchers made attempts to verify drug history directly with the patients or to check the validity of the prescriptions data source; only one study was deemed to have specific validation of drug use. ${ }^{14}$ Most studies reported the accuracy of outcome ascertainment on the basis of historical validation studies; only two studies specifically cross checked or validated outcomes for this analysis. ${ }^{1523}$ Both of these studies showed a limited degree of misclassification. ${ }^{1523}$

None of the studies provided details about the severity and consequences of the cardiac adverse events. Almost all the studies used a wide variety of variables to adjust for potential confounders. Two cohort studies checked specifically for similarities between the rosiglitazone and pioglitazone populations and did not find any major differences in the characteristics evaluated. ${ }^{1719}$ We were able to use adjusted risk estimates for most studies, except for two studies for which we calculated odds ratios from the raw data. ${ }^{1821}$

\section{Myocardial infarction}

Compared with pioglitazone, use of rosiglitazone was associated with a significantly increased odds of myocardial infarction from 15 studies (pooled odds ratio $1.16,95 \%$ confidence interval 1.07 to $1.24 ; \mathrm{P}<0.001$ ) (fig 2). We found a moderate level of heterogeneity $\left(\mathrm{I}^{2}=46 \%\right)$ for the pooled results for myocardial infarc tion, which stemmed from combining the unadjusted and adjusted studies together for the overall estimate.

\section{Heart failure}

Based on the pooled results of eight studies, the odds of congestive heart failure were statistically significantly higher for rosiglitazone than for pioglitazone (odds ratio $1.22,1.14$ to $1.31 ; \mathrm{P}<0.001)$, with moderate statistical heterogeneity $\left(\mathrm{I}^{2}=37 \%\right)$ (fig 3$)$.

\section{Overall mortality}

The odds of death were statistically significantly higher for rosiglitazone than for pioglitazone when we pooled eight studies, with an odds ratio of 1.14 (1.09 to 1.20 $\mathrm{P}<0.001$ ) (fig 4). We found no evidence of statistical heterogeneity for this outcome $\left(\mathrm{I}^{2}=0 \%\right)$.

\section{Number needed to treat for harm}

In a low risk population (age 45-64 years) with type 2 diabetes but no previous history of myocardial infarction, the underlying incidence of myocardial infarction 


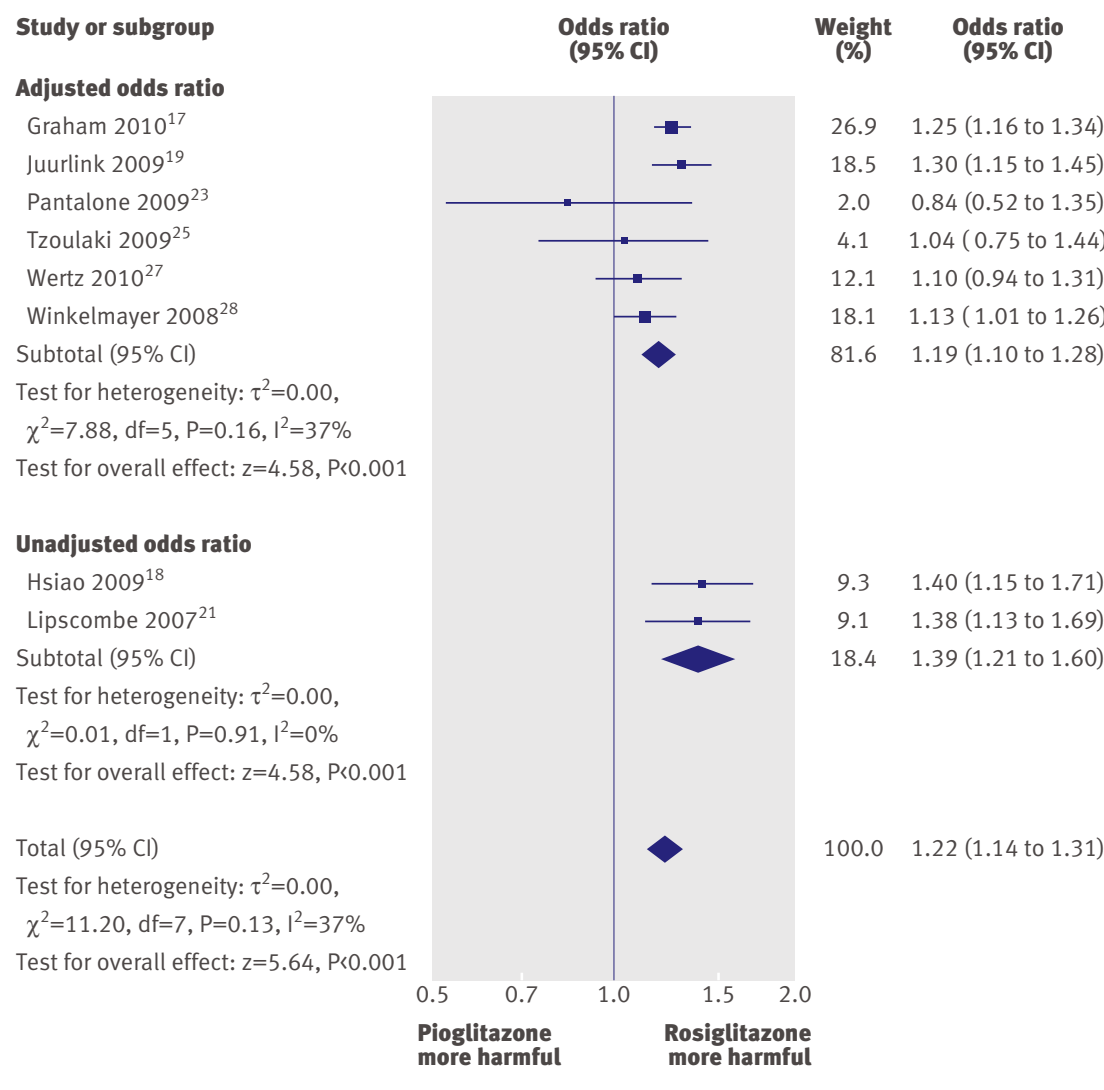

Fig 3 | Meta-analysis of odds ratio for heart failure with rosiglitazone versus pioglitazone

was $1.08 \%$ per year. ${ }^{30}$ Use of rosiglitazone here would result in an annual NNH of 587 (95\% confidence interval 392 to 1339$)$. This can be equated to 170 excess myocardial infarctions for every 100000 patients who received rosiglitazone rather than pioglitazone.

In a US cohort of patients with type 2 diabetes, the baseline incidence of heart failure was found to be $3.08 \%$ per year. ${ }^{31}$ Use of rosiglitazone here would result in an annual $\mathrm{NNH}$ of 154 (110 to 241). This can be equated to 649 excess cases of heart failure for every 100000 patients who received rosiglitazone rather than pioglitazone.

In a large French registry study of patients with type 2 diabetes and atherosclerosis, the underlying mortality rate was found to be $3.15 \%$ per year. ${ }^{32}$ Use of rosiglitazone here would result in an annual NNH of 232 (163 to 360). This can be equated to 431 excess deaths for every 100000 patients who received rosiglitazone rather than pioglitazone.

\section{Sensitivity analysis}

Meta-analysis using the fixed effects model yielded estimates that were similar in direction and magnitude to those from the random effects model for myocardial infarction (odds ratio $1.15,1.10$ to 1.21 ), heart failure $(1.23,1.17$ to 1.29$)$, and overall mortality $(1.14,1.09$ to $1.20)$.

In view of potential patient selection bias arising after publication of a meta-analysis in May 2007 that showed increased myocardial risk with rosiglitazone, ${ }^{33}$ we did a post hoc analysis by excluding the single study that had a substantial proportion of patients recruited after May 2007. ${ }^{17}$ This did not appreciably change the direction and magnitude of the estimates for myocardial infarction (odds ratio $1.17,1.08$ to 1.27 ), heart failure $(1.21,1.10$ to 1.33$)$, and overall mortality (1.13, 1.04 to 1.24). Further exclusion of another study (recruitment dates 2002 to 2008) did not appreciably change the odds ratios for myocardial infarction (1.19, 1.09 to 1.29$)$, heart failure $(1.18,1.06$ to 1.33$)$, and overall mortality $(1.14,1.06$ to 1.22$){ }^{19}$

\section{Assessment of publication bias}

The funnel plot showed that risk estimates stemmed mostly from large, precise studies that seemed to be fairly well distributed, with no definite evidence of asymmetry (fig 5).

\section{DISCUSSION}

Our results suggest a modest but statistically significant increase in the odds of myocardial infarction (approximately $16 \%$ ), congestive heart failure (approximately $23 \%$ ), and mortality (approximately 14\%) with use of rosiglitazone compared with those for pioglitazone use in real world studies among patients with type 2 diabetes. The consistency in the magnitude of increased risk for the different cardiac outcomes, as well as mortality, indicates that this is unlikely to be a chance finding. Other strengths of our analysis include the large number of thiazolidinedione users (around 810000) and the absence of substantial statistical heterogeneity, which suggests that the risk is maintained across most populations and is unaffected by geographical variations.

\section{Comparison with other studies}

Our synthesis of evidence from observational studies extends the findings of a cardiovascular hazard with rosiglitazone from meta-analysis of clinical trials to real world settings and suggests the possibility of a cardiovascular difference between the two drugs. ${ }^{3-5}$ Adjusted indirect comparisons of the risk estimates from meta-analysis of myocardial infarction and heart failure in randomised controlled trials shows that rosiglitazone is associated with an increased relative risk of 1.58 (95\% confidence interval 1.14 to 2.20$)$ for myocardial infarction and 1.48 (1.01 to 2.18) for heart failure, compared with pioglitazone..$^{3-534}$ The direction of effect for both outcomes is consistent with our analysis, whereas the relatively lower point estimates seen in our analysis may reflect the generally more conservative nature of estimates of harm that has been noted with observational studies. ${ }^{35}$ Participants in trials may differ from those in observational studies, because most of the observational studies recruited a wider, more generalisable range of patients by not enforcing rigid inclusion and exclusion criteria relating to comorbid conditions. Of the 16 included studies, two excluded patients with existing cardiac conditions (so that they could study incident disease $)^{2023}$ and only one excluded patients who had comorbidities such as renal or liver disease. 
Table 2|Drug use, study outcomes, and potential sources of bias

Studies

Bilik $2010^{14}$

\section{Ascertainment of drug use}

Ascertained by health plan records for prescriptions filled; average of 19 months' use

Brownstein Based on electronic records and $2010^{15}$ randomly checked case notes/ discharge summaries, with $94 \%$ sensitivity and specificity for drug use

Dormuth $2009^{16}$ Pharmanet database of prescriptions dispensed at community pharmacies (data quality checks done by Pharmane

Graham 2010 $\quad$ Drug claims linked to Medicare database for prescription drugs from January 2006; median followup 105 days

\section{Hsiao $2009^{18} \quad$ Mean use of around 450 days} ascertained with prescription claims

Juurlink $2009^{19} \quad$ Follow-up median of 292 days for rosiglitazone and 294 days for pioglitazone; ascertainment based on computerised prescription records

Koro $2008^{20} \quad$ Follow-up mean of 2.1 years with drug use window of 3 months, inferred from prescription claims

\begin{tabular}{ll}
\hline Lipscombe & Unclear ascertainment; median \\
$2007^{21}$ & follow-up 3.8 years
\end{tabular}

Margolis $2008^{22}$ Thiazolidinedione use on average 3.5 years; data based on computerised prescription records

Pantalone $2009^{23}$ Drug use at baseline based on database information at single healthcare centre

\section{Stockl $2009^{24} \quad$ Drug use based on prescription} claims from pharmacy database

Tzoulaki $2009^{25}$ Drug use based on database information; median follow-up 7.1 years

Walker $2008^{26} \quad$ Drug use from PharMetrics database; mean on-treatment tim 8 months and overall follow-up ranged from 12 to 18 months

Wertz $2010^{27}$ Drugs from pharmacy records; unclear ascertainment; mean duration of treatment 14.6 months

MI based on hospital discharge diagnosis and ICD code as primary event

\section{Ascertainment of outcomes}

$\mathrm{MI}$ and all cause mortality ascertained by ICD codes on health plan administrative data and national death index

MI ascertainment based on ICD codes and randomly selected case notes/discharge summaries with sensitivity of $94 \%$ and specificity of $74 \%$ for outcomes

MI ascertainment based on ICD codes of hospital admission records (primary reason for admission) collected by Ministry of Health; controls were patient starting metformin matched on age, sex, number of family members, health plan enrolment, and income

MI and heart failure based on ICD discharge codes with positive predictive values of $>90 \%$; mortality ascertained by linkage to social security master beneficiary record database, which captures $95 \%$ of deaths for older people

MI and heart failure ascertainment based on ICD codes Data used in unadjusted form in meta-analysis for inpatient claims

All cause mortality, MI, and heart failure obtained from national ambulatory care reporting system database, Canadian Institute for Health information discharge database, and Ontario health insurance database

Cases had ICD code for hospital admission for $M$ occurring $\geq 3$ months after diagnosis of diabetes; controls were randomly selected from eligible matched patients within cohort who did not have ICD code for MI

$\mathrm{MI}$, heart failure, and mortality data from registered persons databases and hospital discharge summary abstract database

$\mathrm{MI}$ and coronary artery disease (MI, unstable angina, cardiac death, coronary artery reperfusion procedure) based on computerised read codes in general practice database; approximately $3 \%$ lost to follow-up

Heart failure and mortality data from ICD codes and electronic health records database; small proportion of mortality records from social security death index had errors on cross checking and were corrected for analysis

MI cases based on ICD codes for hospital admission; controls were matched on various parameters with specific group constructed for analysis of rosiglitazone $\checkmark$ pioglitazone

MI, heart failure, and mortality; unclear outcome ascertainment

MI, heart failure, and mortality from medical claims, ICD codes, and national death index plus database; mean follow-up 19.6 months \begin{tabular}{lll}
\hline Winkelmayer & Drug use based on national drug & Unclear how mortality was ascertained; MI and heart \\
$2008^{28}$ & codes for prescription claims; mean & failure data from Medicare claims
\end{tabular} drug use around 215 days

Ziyadeh $2009^{29} \quad$ Use ascertained from pharmacy claims database; mean follow-up 8.4 months with regimen stop as censoring event

MI data from hospital discharge diagnosis and ICD code as primary event; "sudden death" events captured through ambulance codes for resuscitation/ intubation

\section{Adjustment for confounders}

Age, sex, race, income, history of diabetic nephropathy, history of cardiovascular disease, insulin use, and health plan

Age, sex, cardiovascular disease, antihypertensive and lipid lowering drugs, and Charlson score

Duration of diabetes; congestive heart failure; angiography; revascularisation; ischaemic stroke; TIA; previous $\mathrm{MI}$; angina; renal disease; Romano comorbidity score; use of cardiac drugs, clopidogrel, and insulin; and past use of metformin, glitazones, and sulfonylureas

Sex, age, race, low income, extended care, Charlson score, cardiovascular disease and drugs, lipid lowering drugs, and comorbidities

Age, sex, residence, socioeconomic status, year of entry, duration of diabetes, acute $\mathrm{MI}$, angina, congestive heart failure, coronary angiography, CABG, $\mathrm{PCl}$, Charlson index, history of renal disease, and previous drugs (antihypertensives, aspirin, NSAIDs, nitroglycerin preparations, statins, oral hypoglycaemics, digoxin)

Age; use of ACE inhibitors, $\beta$ blockers, diuretic, or nitrate; hyperlipidaemia; hypertension; and CAD

Data used in unadjusted form in meta-analysis

Age; sex; $\mathrm{BMI}$; $\mathrm{HbA}_{1 \mathrm{c}}$; smoking; chronic kidney disease; eGFR; mean arterial blood pressure; and history of $\mathrm{MI}$, unstable angina, or cardiac procedure

Age, sex, race, eGFR, albumin/urine creatinine ratio, $\mathrm{HbA}_{1 \mathrm{C}}, \mathrm{BMI}$, systolic blood pressure, diastolic blood pressure, HDL, LDL, triglycerides, smoking status, cardiovascular drugs, new diabetes, and median household income

Age, cardiovascular risk score, non-cardiovascular acute hospital admission, COPD, and use of oestrogen therapy

Age, sex, duration of diabetes, complications of diabetes, cardiovascular and peripheral artery disease, co-prescribed drugs, BMI, cholesterol concentration, systolic blood pressure, $\mathrm{HbA}_{1 \mathrm{C}}$, creatinine concentration, albumin concentration, and smoking status

Propensity score used to adjust according to demographics, calendar time, use of antidiabetic drugs, history of $\mathrm{MI}$, coronary revascularisation, angina, ACS, congestive heart failure, hyperlipidaemia, hypertension, obesity, smoking, use of cardiovascular drugs

Propensity score used to adjust for age, sex, health plan, Deyo-Charlson comorbidity index score, cardiovascular and peripheral vascular disease, cardiovascular and antidiabetic drugs, obesity, smoking status, and diabetic complications

Cardiovascular disease, cerebrovascular disease, congestive heart failure, previous insulin treatment, and nitrate use

Propensity score matching used with adjusted analysis for variety of demographic and cardiovascular risk factors

$A C S=$ acute coronary syndrome; $B M I=$ body mass index; $C A B G=$ coronary artery bypass graft; $C A D=$ coronary artery disease; $C O P D=c h r o n i c$ obstructive pulmonary disease; eGFR=estimated glomerular filtration rate; $\mathrm{HbA}_{1 \mathrm{c}}=$ glycated haemoglobin; $\mathrm{HDL}=$ high density lipoprotein cholesterol; ICD=international classification of diseases; $L D L=$ low density lipoprotein cholesterol; $\mathrm{MI}=$ myocardial infarction; NSAID=non-steroidal anti-inflammatory drug; $\mathrm{PCl}=$ percutaneous coronary intervention; $\mathrm{TI} A=$ transient ischaemic attack. 
Study or subgroup

Adjusted odds ratio Bilik $2010^{14}$

Graham $2010^{17}$

Juurlink $2009^{19}$

Pantalone $2009^{23}$

Tzoulaki $2009^{25}$

Wertz $2010^{27}$

Winkelmayer $2008^{28}$

Subtotal $(95 \% \mathrm{Cl})$

$\chi^{2}=4.83, \mathrm{df}=6, \mathrm{P}=0.57, \mathrm{I}^{2}=0 \%$

Test for overall effect: $z=5.05, P<0.001$

\section{Unadjusted odds ratio}

Lipscombe $2007^{21}$

Subtotal $(95 \% \mathrm{Cl})$

Test for overall effect: $z=1.15, P=0.25$

\section{Total $(95 \% \mathrm{Cl})$}

Test for heterogeneity: $\tau^{2}=0.00$,

$\chi^{2}=4.85, \mathrm{df}=7, \mathrm{P}=0.68, \mathrm{I}^{2}=0 \%$

Test for overall effect: $z=5.18, P<0.001$
Test for heterogeneity: $\tau^{2}=0.00$,

Test for heterogeneity: Not applicable

\section{Weight Odds ratio (\%) (95\% Cl)}

$(95 \% \mathrm{Cl})$

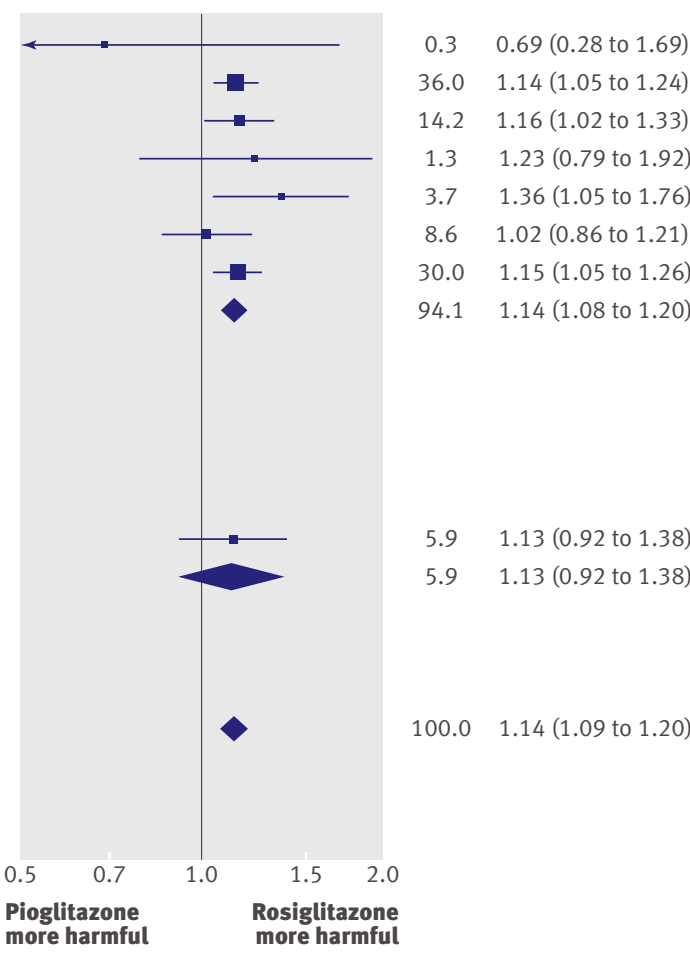

Fig $4 \mid$ Meta-analysis of odds ratio for overall mortality with rosiglitazone versus pioglitazone

As both drugs are known to cause heart failure, the increased risk of congestive heart failure associated with rosiglitazone compared with pioglitazone represents its differential cardiovascular toxicity. Two interpretations for their differential effects on myocardial infarction are possible. One possibility is that these findings represent an ischaemic cardiovascular benefit with pioglitazone. However, conclusive evidence on ischaemic cardiovascular benefit with pioglitazone is lacking; a metaanalysis of trials yielded a relative risk of 0.81 (0.64 to 1.02) for myocardial infarction. The other possibility is a greater ischaemic cardiovascular hazard with rosiglitazone, consistent with evidence from clinical trials. ${ }^{34}$

\section{Possible biological mechanism}

The precise biological mechanisms responsible for these differences in cardiovascular risk and mortality are uncertain. Significant differences have been found between the thiazolidinediones in lipid metabolism; rosiglitazone causes greater elevations of triglycerides and low density lipoprotein cholesterol than does pioglitazone. ${ }^{36}$ Pioglitazone had a significantly more favourable effect on triglycerides, high density lipoprotein cholesterol, low density lipoprotein particle concentration, and low density lipoprotein particle size than did rosiglitazone. Whereas pioglitazone has shown some potential benefit in preventing progression of atherosclerosis, ${ }^{37}$ rosiglitazone failed to show any significant effect in preventing atherosclerosis in a recent study. ${ }^{38}$ The more powerful renal PPAR $\gamma$ agonistic effect of rosiglitazone, leading to more fluid retention, may explain its greater risk of congestive heart failure. $^{3940}$

\section{Clinical and policy implications}

Our findings have important implications. Rosiglitazone is still available on a restricted basis in the United States and Canada. ${ }^{841}$ However, for patients who need thiazolidinedione treatment, continued use of rosiglitazone may lead to excess heart attacks, heart failure, and mortality, compared with pioglitazone. The size of the effect on public health may be considerable, given the data from June 2009 showing that about 3.8 million prescriptions for rosiglitazone were dispensed annually in the United States. ${ }^{42}$ However, other adverse effects are associated with both the thiazolidinediones, such as the doubling of risk of fracture in women. ${ }^{7}$ Concerns also exist about a modest increase in the risk of bladder cancer with pioglitazone after long term use in an observational study and a higher percentage of bladder cancers with pioglitazone relative to comparator arms in long term randomised controlled trials. ${ }^{43}$ Further studies are needed to investigate these other adverse events, as clinicians need to balance these risks and benefits against those of emerging alternative agents such as incretin mimetics that may or may not be safer than thiazolidinediones.

\section{Limitations of study}

Our analysis has some limitations, relating mainly to the quality of the primary studies. Misclassification of outcomes and drug use may occur in observational studies that rely on healthcare databases and discharge codes. However, any potential misclassification of drug use and outcomes would affect both thiazolidinediones equally. Non-randomised data are susceptible to selection bias and residual confounding. However, investigators of the two largest cohort studies found little difference in the baseline demographics and cardiovascular risk of patients who used pioglitazone and rosiglitazone. ${ }^{1719}$ Both drugs are from the same class and were licensed for similar indications. Until May 2007, no reasons existed why any specific group of patients would have been systematically channelled towards one thiazolidinedione or the other. Our risk estimates did not change despite exclusion of the two

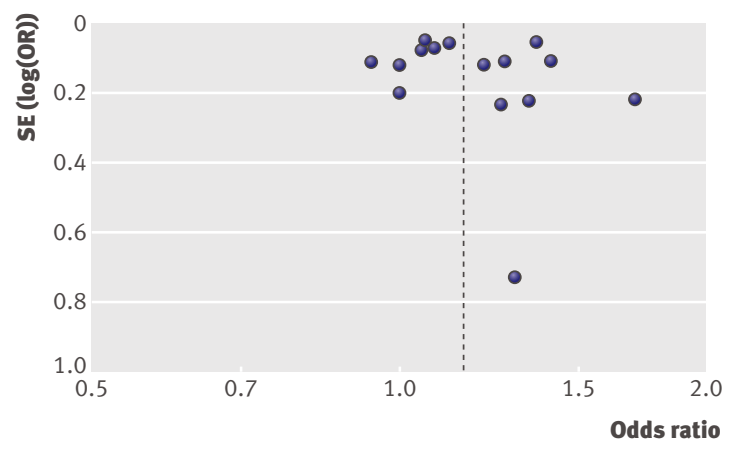

Fig 5 Funnel plot based on odds ratio for myocardial infarction and study precision 


\section{WHAT IS ALREADY KNOWN ON THIS TOPIC}

Both rosiglitazone and pioglitazone are known to increase the risk of congestive heart failure

However, the risk of ischaemic cardiovascular events seems to have been mainly associated with rosiglitazone rather than pioglitazone

Any distinct differences between the cardiovascular effects of the thiazolidinediones have yet to be fully clarified

\section{WHAT THIS STUDY ADDS}

In observational studies, rosiglitazone is associated with increased odds of congestive heart failure, myocardial infarction, and death compared with pioglitazone

studies that recruited after May 2007. ${ }^{1719}$ Potential exists for bias in selection of outcomes for analysis. However, although selective reporting favouring significant beneficial outcomes may occur, one cannot assume that reporting bias is similarly focused on significant findings of harm. The converse may occur with competing interests that emphasise interpretation and reporting of safety in a manner that is favourable to rosiglitazone. ${ }^{44}$ Finally, we had insufficient data to assess effects on stroke or death from cardiac causes.

\section{Conclusions}

Our results show that among patients with type 2 diabetes, use of rosiglitazone is associated with a modest but statistically significant increase in the odds of myocardial infarction, congestive heart failure, and death compared with patients receiving pioglitazone in real world settings. Clinicians, patients, and regulatory authorities should carefully consider these results in the context of the available information on the thiazolidinediones' benefits on glycaemic control and harm relating to different outcomes.

Contributors: YKL, CSK, and SS developed the concept and protocol for the review. CSK and YKL abstracted and analysed data. YKL, CSK, and SS wrote the manuscript. YKL had full access to all of the data in the study, takes responsibility for the integrity of the data and the accuracy of the data analysis, and is the guarantor.

Funding: SS is supported by grant number 1KL2RR025006-03 from the NCRR, a component of the National Institutes of Health $(\mathrm{NIH})$, and $\mathrm{NIH}$ Roadmap for Medical Research. The design and conduct of the study; collection, management, analysis, and interpretation of the data; and preparation, review, and approval of the manuscript was independent of any sources of funding. Its contents are solely the responsibility of the authors and do not necessarily represent the official view of NCRR or NIH Competing interests: All authors have completed the Unified Competing Interest form at http://www.icmje.org/coi_disclosure.pdf (available on request from the corresponding author) and declare that (1) they have no relationships with any company that might have an interest in the submitted work in the previous three years; (2) their spouses, partners, or children have no financial relationships that may be relevant to the submitted work; and (4) they have no non-financial interests that may be relevant to the submitted work.

Data sharing: No additional data available.

1 Gale EA. Lessons from the glitazones: a story of drug development. Lancet 2001:357:1870-5.

2 Nissen SE, Wolski K, Topol EJ. Effect of muraglitazar on death and major adverse cardiovascular events in patients with type 2 diabetes mellitus. JAMA 2005:294:2581-6.

3 Nissen SE, Wolski K. Rosiglitazone revisited: an updated metaanalysis of risk for myocardial infarction and cardiovascular mortality. Arch Intern Med 2010;170:1191-201.

4 Singh S, Loke YK, Furberg CD. Long-term risk of cardiovascular events with rosiglitazone: a meta-analysis. JAMA 2007;298:1189-95.
5 Lincoff AM, Wolski K, Nicholls SJ, Nissen SE. Pioglitazone and risk of cardiovascular events in patients with type 2 diabetes mellitus: a meta-analysis of randomized trials. JAMA 2007;298:1180-8.

6 Singh S, Loke YK, Furberg CD. Thiazolidinediones and heart failure: a teleo-analysis. Diabetes Care 2007;30:2148-53.

7 Loke YK, Singh S, Furberg CD. Long-term use of thiazolidinediones and fractures in type 2 diabetes: a meta-analysis. CMAJ 2009;180:32-9.

8 Cohen D. Insiders criticise FDA's decision not to withdraw rosiglitazone. BMJ 2010;341:c5333.

9 Misbin Rl. Lessons from the Avandia controversy: a new paradigm fo the development of drugs to treat type 2 diabetes. Diabetes Care 2007;30:3141-4.

10 Loke YK, Price D, Herxheimer A. Adverse effects. In: Higgins JPT, Green S, eds. Cochrane handbook for systematic reviews of interventions. John Wiley \& Sons, 2008.

11 Davies HT, Crombie IK, Tavakoli M. When can odds ratios mislead? BMJ 1998;316:989-91.

12 Cates Cl. Dr Chris Cates EBM website. 2010. www.nntonline.net.

13 Deeks JJ, Higgins JP, Altman DG. Analysing data and undertaking meta-analyses. In: Higgins JPT, Green S, eds. Cochrane handbook fo systematic reviews of interventions. John Wiley \& Sons, 2008.

14 Bilik D, McEwen LN, Brown MB, Selby JV, Karter AJ, Marrero DG, et al. Thiazolidinediones, cardiovascular disease and cardiovascular mortality: translating research into action for diabetes (TRIAD). Pharmacoepidemiol Drug Saf 2010;19:715-21.

15 Brownstein JS, Murphy SN, Golfine AB, Grant RW, Sordo M, Gainer V, et al. Rapid identification of myocardial infarction risk associated with diabetes medications using electronic medical records. Diabetes Care 2010;33:526-31.

16 Dormuth CR, Maclure M, Carney G, Schneeweiss S, Bassett K, Wright JM. Rosiglitazone and myocardial infarction in patients previously prescribed metformin. PLoS One 2009;4:e6080.

17 Graham DJ, Ouellet-Hellstrom R, MaCurdy TE, Ali F, Sholley C, Worral C, et al. Risk of acute myocardial infarction, stroke, heart failure and death in Medicare patients treated with rosiglitazone or pioglitazone. JAMA 2010;304:411-8

18 Hsiao FY, Huang WF, Wen YW, Chen PF, Kuo KN, Tsai YW. Thiazolidinediones and cardiovascular events in patients with type 2 diabetes mellitus: a retrospective cohort study of over 473,000 patients using the national health insurance database in Taiwan. Drug Saf 2009;32:675-90.

19 Juurlink DN, Gomes T, Lipscombe LL, Austin PC, Hux JE, Mamdani MM. Adverse cardiovascular events during treatment with pioglitazone and rosiglitazone: population based cohort study. BM 2009;339:b2942.

20 Koro CE, Fu Q, Stender M. An assessment of the effect of thiazolidinedione exposure on the risk of myocardial infarction in type 2 diabetic patients. Pharmacoepidemiol Drug Saf 2008;17:989-96.

21 Lipscombe LL, Gomes T, Levesque LE, Hux JE, Juurlink DN, Alter DA. Thiazolidinediones and cardiovascular outcomes in older patients with diabetes. JAMA 2007;298:2634-43.

22 Margolis DJ, Hoffstand O, Strom BL. Association between serious ischemic cardiac outcomes and medications used to treat diabetes. Pharmacoepidemiol Drug Saf 2008;17:753-9.

23 Pantalone KM, Kattan MW, Yu C, Wells BJ, Arrigain S, Jain A, et al. The risk of developing coronary artery disease or congestive heart failure, and overall mortality, in type 2 diabetic patients receiving rosiglitazone, pioglitazone, metformin, or sulfonylureas: a retrospective analysis. Acta Diabetol 2009;46:145-54.

24 Stockl KM, Le L, Zhang S, Harada AS. Risk of acute myocardial infarction in patients treated with thiazolidinediones or other antidiabetic medications. Pharmacoepidemiol Drug Saf 2009;18:166-74.

25 Tzoulaki I, Mokokhia M, Curcin V, Little MP, Millett Cl, Ng A, et al. Risk of cardiovascular disease and all cause mortality among patients with type 2 diabetes prescribed oral antidiabetes drugs: retrospective cohort study using UK general practice research database. BM/ 2009;3339:b4731.

26 Walker AM, Koro CE, Landon J. Coronary heart disease outcomes in patients receiving antidiabetic agents in the PharMetrics database 2000-2007. Pharmacoepidemiol Drug Saf 2008;17:760-8.

27 Wertz DA, Chang CL, Sarawate CA, Willey VJ, Cziraky MJ, Bohn RL. Risk of cardiovascular events and all-cause mortality in patients treated with thiazolidinediones in a managed-care populations. Circ Cardiovasc Qual Outcomes 2010;3:538-45.

28 Winkelmayer WC, Setoguchi S, Levin R, Solomon DH. Comparison of cardiovascular outcomes in elderly patients with diabetes who initiated rosiglitazone vs pioglitazone therapy. Arch Intern Med 2008;168:2368-75.

29 Ziyadeh N, McAfee AT, Koro C, Landon J, Arnold Chan K. The thiazolidinediones rosiglitazone and pioglitazone and the risk of coronary heart disease: a retrospective cohort study using the US health insurance database. Clin Ther 2009;31:2665-77. 
30 Lee CD, Folsom AR, Pankow JS, Brancati FL, for the Atherosclerosis Risk in Communities (ARIC) Study Investigators. Cardiovascular events in diabetic and nondiabetic adults with or without history of myocardial infarction. Circulation 2004;109:855-60.

31 Nichols GA, Gullion CM, Koro CE, Ephross SA, Brown JB. The incidence of congestive heart failure in type 2 diabetes: an update. Diabetes Care 2004;27:1879.

32 Roussel R, Travert F, Pasquet B, Wilson PW, Smith SC Jr, Goto S, et al, for the Reduction of Atherothrombosis for Continued Health (REACH) Registry Investigators. Metformin use and mortality among patients with diabetes and atherothrombosis. Arch Intern Med 2010;170:1892-9.

33 Nissen SE, Wolski K. Effect of rosiglitazone on the risk of myocardia infarction and death from cardiovascular causes. N Engl J Med 2007;356:2457-71.

34 Song F, Altman DG, Glenny AM, Deeks JJ. Validity of indirect comparison for estimating efficacy of competing interventions: empirical evidence from published meta-analyses. $B M J$ 2003;326:472.

35 Papanikolaou PN, Christidi GD, loannidis JPA. Comparison of evidence on harms of medical interventions in randomized and nonrandomized studies. CMAJ 2006;174:635-41.

36 Goldberg RB, Kendall DM, Deeg MA, Buse JB, Zagar AJ, Pinaire JA, et al, for the GLAl Study Investigators. A comparison of lipid and glycemic effects of pioglitazone and rosiglitazone in patients with type 2 diabetes and dyslipidemia. Diabetes Care 2005;28:1547-54

37 Nissen SE, Nicholls SJ, Wolski K, Nesto R, Kupfer S, Perez A, et al, for the PERISCOPE Investigators. Comparison of pioglitazone vs glimepiride on progression of coronary atherosclerosis in patients with type 2 diabetes: the PERISCOPE randomized controlled trial. JAMA 2008;299:1561-73.

38 Gerstein HC, Ratner RE, Cannon CP, Serruys PW, GarcÃa-GarcÃa HM, van Es GA, et al, for the APPROACH Study Group. Effect of rosiglitazone on progression of coronary atherosclerosis in patients with type 2 diabetes mellitus and coronary artery disease: the assessment on the prevention of progression by rosiglitazone on atherosclerosis in diabetes patients with cardiovascular history trial. Circulation 2010;121:1176-87.

39 Young PW, Buckle DR, Cantello BC, Chapman H, Clapham JC, Coyle PJ, et al. Identification of high-affinity binding sites for the insulin sensitizer rosiglitazone (BRL-49653) in rodent and human adipocytes using a radioiodinated ligand for peroxisomal proliferator-activated receptor gamma. J Pharmacol Exp Ther 1998;284:751-9.

40 Zhang H, Zhang A, Kohan DE, Nelson RD, Gonzalez FJ, Yang T. Collecting duct-specific deletion of peroxisome proliferator-activated receptor gamma blocks thiazolidinedione-induced fluid retention. Proc Natl Acad Sci USA 2005;102:9406-11.

41 Health Canada. Avandia, Avandamet and Avandaryl: important new restrictions on the use of rosiglitazone products due to information on heart-related events. 2010. www.hc-sc.gc.ca/dhp-mps/medeff/ advisories-avis/public/_2010/avandia_6_pc-cp-eng.php.

42 Shah ND, Montori VM, Krumholz HM, Tu K, Alexander GC, Jackevicius CA. Responding to an FDA warning-geographic variation in the use of rosiglitazone. N Engl J Med 2010;10:1056.

43 US Food and Drug Administration. FDA drug safety communication: ongoing safety review of Actos (pioglitazone) and potential increased risk of bladder cancer after two years exposure. 2010. www.fda.gov/ Drugs/DrugSafety/ucm226214.htm.

44 Wang AT, McCoy CP, Murad MH, Montori VM. Association between industry affiliation and position on cardiovascular risk with rosiglitazone: cross sectional systematic review. BMJ 2010;340:c1344.

Accepted: 15 February 2011 